\title{
Hospitais comunitários
}

BERTA NUNES*

Resumo

Neste artigo discute-se o papel dos hospitais de Clínicos Gerais (HCG) ou Hospitais Comunitários no Sistema Nacional de Saúde Português e chama-se a atenção para a ausência de uma política clara sobre o presente e o futuro destes hospitais. Discutem-se algumas vantagens da existência destes hospitais, comparando-os com estruturas semelhantes noutros paises e apontam-se algumas sugestões para o desenvolvimento futuro dos HCG em Portugal.

Palavras-chave:

Hospitais de Clínica Geral/Hospitais Comunitários; Desenvolvimento Futuro; Papel e Funções.

\section{Introducão}

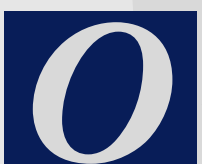
s Hospitais de Clínicos Gerais (HCG) ou Hospitais Comunitários são Hospitais onde os Clínicos Gerais podem internar e tratar os seus doentes, ou mantê-los em observação durante curtos períodos de tempo.

São um recurso importante para as comunidades onde estão sediados mas dado o seu pouco peso e a falta de uma política que defina qual a sua função dentro do S.N.S., são vulneráveis ao encerramento existindo quem defenda que "deverão tendencialmente desaparecer" ${ }^{1}$ ou à mudança da sua utilização propondo algumas "a sua reconversão a prazo... pela sua devolução às misericórdias ou exploração directa do S.N.S. mas sempre vocacionadas

*Assistente Graduada de Clínica Geral, Doutorada em Saúde Comunitária Centro de Saúde Alfândega da Fé para a $3^{\text {a }}$ Idade e/ou para doentes de evolução prolongada". ${ }^{1}$

Este é o estado actual do debate sobre os Hospitais de Clínicos Gerais no nosso país posição que a autora não sustenta, pretendendo com este artigo acrescentar alguns argumentos para o debate, evitando que se deixem fechar estes hospitais por inércia ou por não reconhecimento da sua natureza e da importância das funções que podem desempenhar no S.N.S.

\section{VANTAGENS DOS HOSPITAIS DE CLÍNICOS GERAIS}

Estes hospitais de uma forma geral são lugares familiares para os habitantes da comunidade que servem e são vistos um pouco como os "Cottage Hospital" ingleses que foram definidos por Albert Napper ${ }^{2}$ como um "lugar idêntico ao da casa, diferindo apenas na limpeza, conforto, higiene e ausência de sobreocupação".

Assim os doentes preferem de uma forma geral ficar internados no "seu" hospital do que serem transferidos para o H. Distrital mais próximo. A família pode visitá-los e prestar-lhes alguns cuidados. Tal é verdade principalmente no caso dos doentes terminais em que o acompanhamento e o cuidado do doente são fundamentais para o próprio doente, que não se sente abandonado, e para os familiares que se sentem assim menos culpados e angustiados por o internarem nestas circunstâncias.

A continuidade dos cuidados (o doente é geralmente tratado pelo seu médico de família) é outra das vantagens dos internamentos em Hospitais de Clínicos Gerais.

Vários estudos realizados noutros países com estruturas semelhantes (Finlândia, Reino Unido, Noruega) mostram que o internamento nos $\mathrm{H}$. de Clínicos Gerais é custo-efectivo e que existe uma relação inversa entre a existência de internamentos em Clínica Geral e as transferências para Hospitais de níveis superiores. ${ }^{1-3}$

\section{ALGUNS NÚMEROS}

Em Portugal existem 350 Centros de Saúde e 103 unidades de Internamento (que neste artigo chamo Hospitais de Clínicos Gerais ou Hospitais Comunitários) com uma lotação de 1697 camas.

Em 1996 os Centros de Saúde com internamento representavam 29,3\% do total de Centros de Saúde existentes no país. A frequência de internamento em 1995 foi de 2,8 por 1000 habitantes, a demora média 15,6 e a taxa de ocupação $64,6 \%$. Estes números só por si desmentem a afirmação relativamente frequente 
de que estas unidades de internamento seriam principalmente ocupadas por idosos durante longos períodos de tempo e que esses idosos estariam melhor em lares de $3^{\text {a }}$ Idade ou Hospitais de retaguarda e que por essa razão deveriam ser transferidos para as misericórdias. Os dados que existem sobre a distribuição destes Hospitais mostram que eles existem por todo o país (mapa 1) sendo Castelo Branco e Leiria os distritos com menor número de camas (16 e 43 respectivamente) e Faro e Aveiro os distritos com maior número de camas (183 e 149 respectivamente). O internamento nos Centros de Saúde tem diminuído, passando entre 1989 e 1994 de 49 mil para 27,8 mil doentes saídos 3 doentes saídos por 1000 habitantes, (Conselho de Reflexão sobre a Saúde, Jan 1997) o que mostra que existe uma tendência para o seu desaparecimento. A verificar-se tal, seria uma grave perda para as comunidades servidas por estas estruturas, principalmente comunidades relativamente isoladas, envelhecidas, e com grandes distâncias para serem percorridas até aos H. Distritais mais próximos.

Comparando o panorama nacional com o de outros países que possuem estruturas idênticas como Reino Unido e a Finlândia (Guadro I e II), verificamos que Portugal está numa situação de menor implantação destas estruturas, o que é compreensivel dado que nestes dois países tem existido uma política de apoio ao desenvolvimento destes Hospitais e/ou movimentos fortes no sentido de contrariar o seu encerramento. ${ }^{4}$

Já na Noruega a situação é semelhante à do nosso país tendo o número nos H.C. Gerais sido reduzido de 1000 para menos de 250 nos últimos 20 anos. No entanto,

\section{MAPA CENTRO DE SAÚdE/CAMAS}

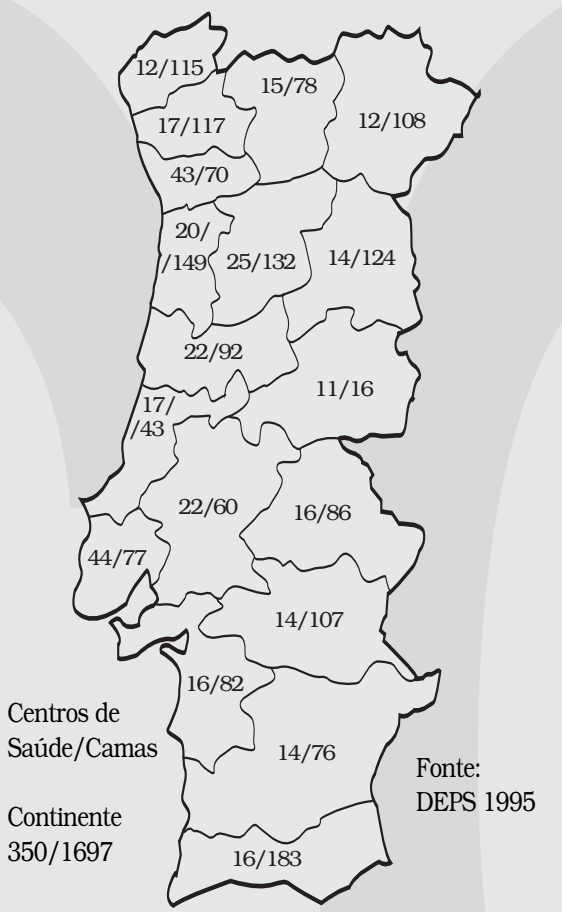

devido aos custos crescentes dos cuidados nos hospitais diferenciados, discute-se as vantagens de voltar a apostar no desenvolvimento dos H.C.G. tanto nas zonas rurais como nas zonas urbanas. ${ }^{3}$

\section{QUADRO I}

HOSPITAIS DE CLÍNICA GERAL COMPARAC̣ÃO C/ A FINLÂNDIA E 0 REINO UNIDO

\begin{tabular}{|lcccc|}
\hline Pais & Ano & $\begin{array}{c}\text { Doentes } \\
\text { Saidos }\end{array}$ & $\begin{array}{c}\text { Demora } \\
\text { média/dias }\end{array}$ & $\begin{array}{c}\text { N. }{ }^{\circ} \\
\text { camas/1000h }\end{array}$ \\
\hline Portugal & 1985 & 57.000 & 12.1 & - \\
\hline Portugal & 1994 & 33.000 & 15.2 & 0.18 \\
\hline Finlândia & 1982 & 197.299 & 30,6 & 2.2 \\
\hline Reino Unido 1983 & 195.202 & 20.1 & 0,25 \\
\hline
\end{tabular}

\begin{tabular}{|lccc|}
\hline \multicolumn{4}{|c|}{ QUADRO II } \\
\hline HOSPITAIS DE CLÍNICA GERAL \\
\hline Pais & Ano & $\begin{array}{r}\text { N. } .^{\text {de }} \\
\text { Hospitais CG }\end{array}$ & $\begin{array}{c}\text { N. }{ }^{\circ} \text { de } \\
\text { Camas }\end{array}$ \\
\hline Finlândia & 1983 & 350 & 8.729 \\
\hline Portugal & 1995 & 103 & 1.697 \\
\hline Reino Unido & 1983 & 443 & 16.385 \\
\hline
\end{tabular}

Roger Jones, 1987 General Pratitioner Beds in Finland, Fonte: DEPS 1995 J.R Coll General Pratitioner, 37, 28-30

\section{QUE TIPO DE DOENTES PODEM SER INTERNADOS NOS HOSPITAIS DE CLINICOS GERAIS?}

Embora em Portugal não existam muitos estudos que permitam responder a esta pergunta, os que existem sugerem que o panorama não será muito diferente do que se passa no Reino Unido e Finlândia. Podemos encontrar nestes hospitais principalemente doentes idosos. Em 1995, 53\% dos doentes internados no C. Saúde de Alfândega da Fé tinham mais de 65 anos um panorama em tudo semelhante ao descrito no Relatório de Actividades da SRS do Distrito de Bragança (1996). ${ }^{1}$

Em alguns destes Hospitais existe a possibilidade de internar idosos durante algum tempo para aliviar os familiares que cuidam deles (que podem eles mesmos adoecer). Tal pode ajudar a manter os idosos por mais tempo em suas casas, apoiando os seus cuidadores. No entanto é necessário definir critérios e limites para esta função apesar de cada caso ser individual e único. Esta função possivelmente variará em importância dependendo dos recursos da comunidade no apoio aos idosos.

Doentes terminais cuja situação ultrapassa as possibilidades do apoio domiciliário ou a possibilidade da própria família cuidar dele em casa, são frequentemente interna- 
dos no C. de Saúde, de forma a que o médico de família possa continuar a cuidar do seu doente e a família pode continuar a prestar-lhe apoio com ajuda da enfermeira. Tal é uma situação muito mais aceitável para os familiares que o internamento em Hospitais Distritais, distantes e estranhos.

Outra categoria de doentes internados nos Hospitais de C. Gerais são doentes transferidos dos H. Distritais ou centrais no pós-operatório ou convalescença de situações estabilizadas.

Uma parte importante dos internamentos são no entanto situações agudas. Num estudo efectuado durante a última semana de Outubro/1996 no C. de Saúde de Alfândega da Fé, foram os seguintes diagnósticos mais frequentes no internamento: AVC, lombociatalgias que não cederam aos AINES no domicílio, depressão, adenocarcinoma gástrico (estado terminal), diabetes descompensados, asma descompensada, etc. (Quadro III).

\section{QUADRO III}

DIAGNÓSTICOS DOS DOENTES INTERNADOS NO CENTRO DE SAÚDE DE ALFÂNDEGA DA FÉ NA ÚLTIMA SEMANA DE OUTUBRO DE 1996

\begin{tabular}{|lc}
\hline Diagnóstico & N. ${ }^{\circ}$ de casos \\
\hline AVC & 2 \\
\hline Lombociatalgia & 2 \\
\hline Depressão & 2 \\
\hline Diabetes descompensada & 1 \\
\hline Adenocarcinoma gástrico (estado terminal) & 1 \\
\hline Doente que vive só (queixas psicossomáticas) & 1 \\
\hline Flebite na perna direita & 1 \\
\hline Gastoenterite/Desidratação & 1 \\
\hline Asma descompensada & 1 \\
\hline Vigilância de traumatismo craniano & 1 \\
\hline (transferido do Hospital Distrital) & 1 \\
\hline Lipotimia & 1 \\
\hline Herpes Zoster & 1 \\
\hline Infecção urinária & 1 \\
\hline Queixas dispépticas (em observação) & 17 \\
\hline TOTAL
\end{tabular}

\section{ALGUNS PROBLEMAS E SUGESTÕES}

Parece-nos importante definir uma politica consistente que reforce e desenvolva os Hospitais de Clínicos Gerais/Hospitais Comunitários dado os serviços relevantes que podem prestar às comunidades que servem, existindo no entanto alguns problemas a ter em conta:

1 - Existem necessidades de formação específicas que neste momento não têm resposta adequada de forma a manter um bom nivel de qualidade no atendimento dos doentes. A maioria destes H.C.G. têm um serviço de urgência que funciona $24 \mathrm{~h}$ por dia e recebe todo o tipo de urgências que transfere quando necessário para os H. Distritais. Este atendimento também pressupõe formação específica que não tem sido fornecida de uma forma planeada e com objectivos claros.

2 -Estes Hospitais necessitam de ser melhor equipados com RX simples e apoio laboratorial para responder mais eficazmente às necessidades dos doentes internados. Seria útil a colaboração e apoio dos especialistas dos Hospitais Distritais mais próximos. $\mathrm{O}$ apoio do fisioterapeuta, e do terapeuta ocupacional seria também útil dada a idade da maioria dos doentes e o apoio que podem dar a doentes que sofrem de patologias frequentes como AVC, ou pós-operatório de fracturas da anca, bem como na reabilitação de doentes com dificuldades nas actividades da vida diária.

3 -Seria importante criar um programa de acreditação específico para pequenos hospitais que tivesse em conta por um lado a sua especificidade e por outro lado a necessidade de garantir a qualidade no atendimento dos doentes.

4 - Os Clínicos Gerais respon- sáveis pela gestão destes hospitais e pelos cuidados dos doentes internados deveriam ser convenientemente remunerados.

5 - As funções destes hospitais deveriam ser definidas de uma forma flexivel, de forma a responder adequadamente às necessidades locais.

Num estudo feito na Finlândia em que se anotou a ocupação das camas dos H.C.G. durante um dia em Março de $1981,{ }^{5} 80 \%$ dos doentes internados tinham mais de 65 anos, mais de $1 / 3$ estavam internados há mais de 1 ano, e cerca de metade destes estavam acamados. As estadas muito prolongadas (mais de um ano) devem-se ao facto de existir um regulamento oficial que determina que $30 \%$ das camas nestes hospitais sejam usados para casos agudos e $70 \%$ para casos crónicos. As doenças cardiovasculares foram o principal diagnóstico no internamento tanto na Finlândia como no Reino Unido ${ }^{5}$ mas destes $10 \%$ correspondem a AVCs no Reino Unido e apenas $4,5 \%$ na Finlândia. Na Finlândia a diabetes e suas complicações representavam $18 \%$ dos internamentos e as infecções do trato urinário e a demência senil representavam respectivamente $14 \%$ e $13 \% .^{5}$

No Reino Unido as infecções respiratórias e a asma representavam $10 \%$ do internamento enquanto na Finlândia a bronquite crónica e a asma em conjunto representaram apenas $5 \%$ dos internamentos. ${ }^{5} \mathrm{Um}$ estudo realizado na Noruega em $1995^{5}$ mostra que os Hospitais de C.G. têm também uma função de tampão evitando que doentes agudos sejam desnecessariamente transferidos para os cuidados secundários, permitindo mantê-los em observação durante curtos períodos de tempo. O mesmo se passa com 
os H.C.G. em Portugal em que frequentemente os doentes são mantidos em observação 24 ou, 48 h permitindo uma melhor avaliação da situação e evitando a sua transferência desnecessária para os cuidados secundários.

\section{Conclusões}

Embora exista a necessidade de mais estudos para caracterizar adequadamente os Hospitais de Clínica Geral portugueses, parece-nos importante reconhecer:

1) que existem

2) que prestam serviços relevantes às populações que servem

3) que devem ser apoiados no seu desenvolvimento e na melhoria de qualidade dos serviços que prestam

4) que deve existir uma política consistente e clara que permite definir o que são e o que podem vir a ser

5) que têm potencialidades ainda não totalmente exploradas no nosso país

6) que existem necesssidades específicas de formação do pessoal (C.G. e enfermeiros) que aí trabalha. 7) que devem ser geridos pelos clínicos gerais com consultadoria e apoio dos especialistas dos $\mathrm{H}$. dis- tritais mais próximos.

\section{Referências Bibliográficas}

1. Kekki P. Analysis of Relation-ships Between Resources and Use of Health Services in Finland. Helsinki: Social Insurence Institution 1979.

2. Baker J. E., Goldacre MJ, Muir Gray JA. Community Hospitals in Oxfordshire: their effect on the use of specialist in patient services J. Epidemol. Community Health, 1986;40:117-126.

3. Aaraas, I. The Finmark General Pratitionar Hospital Study Scand, J. Prim. Health Care, 1995, 13.

4. General Practitioners Hospitals, Royal College of G.P, Ocasional Paper 23. London:RCGP; 1983.

5. Jones, R. 1987, General Pratitioner Beds in Finland - Lessons for U.K? JR Col General Pratitioners, 37, 28-30.

Recebido em 4/6/98

Aceite para publicação em 1/10/98

\section{Endereço para correspondência:} Berta Nunes

Centro de Saúde Alfândega da Fé

5350 Alfândega da Fé

Telef. 279462256

Fax. 279462230

e-mail: bertanunes@mail.telepac.pt

\section{COMMUNITY HOSPITALS}

\section{SUMMARY}

The author discusses the role of the Community Hospitals (C.H) in the Portuguese National Health Service and calls the attention to the absense of a policy concerning the present and future of these hospitals.

We discuss some advantages of these hospitals and compare some Portuguese figures with other countries with similar facilities. Finally the author makes some suggestions concerning the future development of the Community Hospitals in Portugal.

\section{Key words:}

Community Hospitals; Future Development; Role and Function. 